\title{
ПРОФІЛІЗАЦЯ ЗАГАЛЬНОЇ СЕРЕДНЬОЇ ОСВІТИ В КОНТЕКСТІ ІДЕЙ НУШ
}

engineering]. Bulletin of the NTUU "KPI". Series "Mining”. Vol. 30. pp.171-176. [in Ukrainian].

9. Moiseenko, O.(2016). Kultura bezopasnosti: aktualnost, sushchnost i problemy [Culture of safety: relevance, essence and problems]. Occupational Health. Addition. No. 7, pp. 17-31. [in Ukrainian].

10. Pro zatverdzhennia Derzhavnoi prohramy rozvytku mashynobuduvannia na 2006-2011 roky [About approval of the State program of development of mechanical engineering for 2006-2011]: Occupational Health. Appendix Resolution dated April 18, 2006 No. 516 / Cabinet of Ministers of Ukraine. Available at: http:// www.rada.gov.ua.ru/.[in Ukrainian].

11. Stupnytska, N. V. (1999). Pidvyshchennia efektyvnosti planuvannia zakhodiv zapobihannia vyrobnychomu travmatyzmu na pidpryiemstvakh mashynobuduvannia [Improvement of the effectiveness of planning measures to prevent occupational injuries in machine-building enterprises]. Extended abstract of candidate's thesis. Lviv, 22 p. [in Ukrainian].

12. Tairova, T. (2014). Metodolohichni zasady monitorynhu vyrobnychoho travmatyzmu : monohrafiia [Methodological bases of monitoring of occupational injuries: monograph]. Kyiv, 201 p. [in Ukrainian].

13. Chumakova, N. (2015). Ohliad NPAOP u mashynobuduvanni [Review of NPAAP in machine building]. Occupational Health, No. 2, pp.27-30. [in Ukrainian].

Стаття надійшла до редакції 29.07.2019

УДК 373.3/.5.091.21“199”:37.014.5

DOI:

Алла Загородня, кандидат педагогічних наук, доцент, провідний науковий співробітник відділу історії та філософії освіти Інституту педагогіки НАПН України

\section{ПРОФІЛІЗАЦІЯ ЗАГАЛЬНОЇ СЕРЕДНЬОЇ ОСВІТИ В КОНТЕКСТІ ЦДЕЙ НУШ}

У статті висвітлюються питання організачії профільного навчання в системі загальної середньої освіти в умовах впровадження НУШ. Висвітлено стратегічні завдання реформування ланки загальної середньої освіти у відповідності до ідей НУШ. Розкрито сутність поняття “профільне навчання" згідно до визначення Начіональної доктрини розвитку освіти в Україні на 2012 - 2021 рр. Визначено мету та завдання профільного навчання. Окреслено принципи на яких трунтується профільне навчання. Розкрито типи профілізації змісту навчання в закладах загальної середньої освіти. Проаналізовано навчальні плани сучасних закладів загальної середньої освіти Украӥни. Охарактеризовано зміст інваріантного (базового) та варіативного компонентів освіти. Окреслено ичкли навчання нової профільної середньої иколи Згідно до "Концепиії Нової Української школи” (2016 р.).

Ключові слова: НУШ; профілізація; профільне навчання; професійне спрямування; середня освіта.

Лim. 6.

Alla Zahorodnya, Ph.D.(Pedagogy), Associate Professor, Leading Researcher of the History and Philosophy of Education Department Institute of Pedagogics of National Academy of Sciences of Ukraine

\section{PROFILING OF GENERAL SECONDARY EDUCATION} IN THE CONTEXT OF NUSH IDEAS

The article deals with the issues of organization of profile education in the system of general secondary education in the conditions of introduction of NUSH. The strategic tasks of reforming the level of general secondary education in accordance with the ideas of NUSH are highlighted. The essence of the concept "profile education" in accordance with the definition of the National Doctrine of Development of Education in Ukraine for 2012 - 2021 is revealed. The article presents the principles on which the profile training (social equilibrium, continuity and continuity, flexibility, variability, diagnostic and prognostic realization, differentiation, individualization) is based. The list of general secondary education institutions providing vocational training is given and the key aspects of their activity are described. The main components of the formula of the New Ukrainian School are distinguished. The emphasis is not only on the profile content of education, but also on the structural separation of the third degree of general secondary education from the school. Types of profiling of the content of education in general secondary education institutions are revealed. The curricula of modern institutions of general secondary education of Ukraine, which consist of three blocks, are analyzed, namely: general education, profile training, professional practical training. The content of invariant (basic) and variational components of education, which are determined by the central bodies of state administration of education, is characterized. The information on the percentage distribution of basic and variational components of general secondary education is presented. Examples of academic load on a 


\section{ПРОФІЛІЗАЦЯ ЗАГАЛЬНОЇ СЕРЕДНЬОЇ ОСВІТИ В КОНТЕКСТІ ІДЕЙ НУШ}

student by academic and professional profiles of training are given. The cycles of study of the new profile high school are outlined According to the Concept of the New Ukrainian School (2016).

Keywords: NUSH; profiling; profile training; professional orientation; secondary education.

П остановка проблеми. Міжнародна інтеграція, глобалізація та інформатизація у сучасній світовій політиці зумовили відхід від уніфікованої системи освітньої галузі в Україні. Сьогодні старша школа в Україні функціонує як профільна. Відтак, у середніх загальноосвітніх закладах освіти функціонують фізичний, математичний, біолого-хімічний, економічний, географічний, екологічний, правовий, інформаційно-технологічний профілі навчання. Саме за такими профілями передбачає вивчення окремих предметів на одному 3 рівнів: рівні стандарту - окремі предмети не є профільними чи базовими (наприклад, математика в художньоестетичному профілі, історія у фізикоматематичному профілі); академічному рівні окремі предмети не є профільними, але є базовими (наприклад, алгебра і геометрія у фізичному профілі); профільному рівні, який передбачає поглиблене вивчення відповідних предметів, орієнтацію їх змісту на майбутню професію (наприклад, мови та літератури на філологічному профілі).

Проблемі профілізації загальної середньої освіти в Україні приділяється належна увага у психолого-педагогічних дослідженнях багатьох авторів, зокрема, таким її аспектам: висвітленню загальних теоретичних питань профілізації навчання в роботах О. Бугайова, С. Броневщука, М. Бурди, Г. Бунтовської, С. Логачевської, П. Сікорського, Н. Шияна, R. Aldrich, J. Bastian, A. Combe, L. Cremin, M. Curtis, D. Dean, P. Gordon, H. Gudjons, T. O’Brien, G. Walford та ін.; вивченню рівнів, форм і видів профілізації (Н. Ничкало, I. Унт, О. Ярошенко); диференціації змісту навчання школярів та профільній підготовці (Г. Авчіннікова, О. Барановська, Г. Васьківська, С. Дятленко, С. Закірова) та ін.

Метою статті $є$ висвітлення особливостей організації профілізації загальної середньої освіти в Україні, спрямованої на розвиток особистості.

Виклад основного матеріалу. Профільне навчання ми розглядаємо як вид диференційованого навчання, який передбачає врахування освітніх потреб, нахилів та здібностей учнів і створення умов для навчання старшокласників відповідно до їхнього професійного самовизначення, що забезпечується за рахунок змін у цілях, змісті та структурі організації навчання $[1,60]$. Воно має на меті забезпечення рівних освітніх можливостей учнівської молоді до здобуття загальноосвітньої профільної та початкової допрофесійної підготовки; гарантування неперервної освіти впродовж усього життя; виховання особистості, здатної до самореалізації, професійного зростання й мобільності в умовах реформування сучасного суспільства [4].

У “Національній доктрині розвитку освіти в Україні на 2012 - 2021 рр." профілізація трактується як один із шляхів забезпечення рівного доступу дітей до освіти [6].

Серед основних завдань профільного навчання в закладах загальної середньої освіти, слід виокремити: врахування й розвиткок навчальнопізнавальних і професійних інтересів, нахилів, здібностей і потреб учнів; виховання в учнів любові до праці, забезпечення умов для їхнього життєвого і професійного самовизначення, формування готовності до свідомого вибору й оволодіння майбутньою професією; формування соціальної, комунікативної, інформаційної, технічної, технологічної компетенцій учнів на допрофільному рівні, спрямування підлітків щодо майбутньої професійної діяльності; забезпечення наступно-перспективних зв'язків між загальною середньою і професійною освітою відповідно до обраного профілю [4].

Реалізація мети і завдань профільного навчання здійснюється на основі принципів, які обумовлені особистісно орієнтованою, компетентнісною парадигмою освіти і виховання і відображають специфіку профільного навчання на основі таких принципів, як от $[2,146]$ :

- сочіальної рівноваги - передбачає узгодження трьох позицій: можливостей освітніх послуг, запитів ринку праці й соціальних очікувань;

- наступності й неперервності взаємозв'язок між допрофільною підготовкою, профільним навчанням та професійною підготовкою;

- гнучкості - забезпечення можливостей та умов для зміни профілю навчання, змісту і форм організації профільного навчання, у тому числі дистанційного, широкого вибору змісту навчальних програм та можливостей для його корекціі;

- варіативності - багаторівневість навчальних планів, освітніх програм, змісту освіти, використанні різноманітних технологій, надання учням можливості вибору предметів (курсів), що вільно вивчаються, зміні видів діяльності, використанні інтегративного підходу у вивченні обов'язкових предметів;

- діагностико-прогностичної реалізованості 


\section{ПРОФІЛІЗАЦІЯ ЗАГАЛЬНОЇ СЕРЕДНЬОЇ ОСВІТИ В КОНТЕКСТІ ІДЕЙ НУШ}

- виявлення здібностей учнів для обгрунтованої орієнтації на профіль навчання та подальше професійне самовизначення;

- диференціації - забезпечення умов для добровільного вибору школярами профілю навчання, виходячи з їхніх пізнавальних інтересів, здібностей, досягнутих результатів навчання й професійних намірів;

- індивідуалізації-врахування індивідуальних особливостей особистості для досягнення поставленої мети, що слугує основою для здійснення особистісно орієнтованого навчання у профільній школі.

Згідно до “Концепції Нової Української школи” (2016 р.) [5], структура нової профільної середньої школи складається 3 двох циклів, а саме: 10 клас (1 цикл навчання), 11 - 12 класи (2 цикл), що загалом займає 3 роки навчання.

До закладів загальної середньої освіти, що здійснюють навчання за професійним спрямуванням відносять ліцеї академічного та професійного спрямування. Ліцеї академічного спрямування охоплюють учнів певним профільним циклом дисциплін за стандартами їх поглибленого вивчення. Натомість ліцеї професійного спрямування охоплюють певним профільним циклом професійних курсів за стандартами, передбаченими для їх професійної сертифікації. Крім того, ці ліцеї надають додаткову можливість для тих, хто планує вступати до закладу вищої освіти, за наявності не менше ніж 14 таких осіб, пройти цільове додаткове навчання за програмами поглибленого вивчення спорідненого даному ліцею предметного профілю.

Серед основних компонентів формули “Нової української иколи” виокремлюють: новий зміст освіти, заснований на формуванні компетентностей необхідних для успішної самореалізації в суспільстві; наскрізний процес навчання який формує цінності; партнерські стосунки між учителем та учнем; набуття компетентностей для життя; загальнокультурна грамотність; свобода прояву творчості; орієнтація на потреби учня (дитиноцентризм) та ін.

Слід зазначити, що наразі в Україні налагоджується робота щодо формування мережі старших профільних шкіл, що є одним із головних викликів реформи НУШ.

Акцентується увага не лише на профільному змісті навчання, але й на структурному відокремленні III-го ступеню загальної середньої освіти від школи як такої у формат окремих закладів виключно для старшокласників (10 - 12 класи). При цьому зі збереженням їх у рамках єдиної державної системи загальної середньої освіти. Ці заклади (академічні і професійні ліцеї та професійні коледжі) мають працювати виключно як окремі юридичні особи. Таке відокремлення, у першу чергу, потрібне заради впровадження відповідних віковим особливостям здобувачів освіти форм здійснення навчання та шляхів переходу до дорослих форм здобуття подальшої професійної освіти: вищої та робітничотехнологічно-сервісної.

Ліцеї та коледжі мають сприйматися суспільством, як такий етап освіти, що вже не $\epsilon$ шкільним, але ще не $є$ і університетським. Означена Концепція зорієнтована на організацію діяльності старшої школи (10 - 12 класи) виключно як окремої ланки національної системи загальної середньої освіти на засадах реалізації чинників, здатних забезпечити якісно новий рівень освіти школярів у масових вимірах завдяки системному врахуванню.

Для забезпечення на перехідному етапі додаткового адаптаційного періоду для остаточного вибору профілю в перший рік навчання (10-й клас) усі предмети вивчаються за програмами першого року їх поглибленого вивчення. Так, завдяки зануренню у зміст високих предметних вимог, кожен ліцеїст зможе отримати об'єктивну картину своєї профільно орієнтованої спроможності. 3 другого року (11-й клас) зміна профілю виключається.

У старшій школі застосовують такі типи профілізації змісту навчання: 1) навчальні предмети поділяються на окремі галузі знань (гуманітарні, фізико-технічні, природничі); 2) до обов'язкових предметів додаються предмети, які учні вивчають за власним вибором. Також здібні учні мають можливість паралельно з курсом середньої школи вивчати певні предмети, які викладаються у відповідних закладах вищої освіти.

Навчальні плани сучасних закладів загальної середньої освіти України відрізняються один від одного, адже структура цих планів відповідає різній практичній меті шкіл. Разом з тим, в навчальних планах можна виділити три основні блоки: блок загальноосвітньої підготовки, блок профільного навчання, блок професійної практичної підготовки.

Наразі в Україні встановлено інваріантний (базовий) та варіативний компоненти освіти, які визначаються центральними органами державного управління освіти на підставі співвідношення відповідно $(70 \div 80) \%$ (базовий) та $(30 \div 20) \%$ (варіативний) $[3,45]$.

Проте з приходом “Концепції Нової Української школи”, відсоток базового та варіативного 


\section{ПРОФІЛІЗАЦЯ ЗАГАЛЬНОЇ СЕРЕДНЬОЇ ОСВІТИ В КОНТЕКСТІ ІДЕЙ НУШ}

компонентів освіти зазнає змін. Згідно з концепцією НУШ, до 2023 року має бути прийнятий новий стандарт профільної школи, до 2025-ого сформована мережа закладів III ступеня, а до 2027-ого - повноцінний запуск профільної школи. Максимальне навантаження на одного учня на тиждень за академічним та професійним профілями складатиме 33 години на тиждень.

Для прикладу індивідуальна освітня траєкторія учня (максимальне навантаження 33 год/ тиждень) за академічним профілем навчання:

- обов'язковий навчальний напрям - 50 \% (16,5 год/тиждень) для вивчення предметів академічного циклу для отримання атестату;

- індивідуальний навчальний напрям: 30\% (9,9 год/тиждень) для вивчення індивідуально обраних предметів із обов'язкового навчального напряму для досягнення освітніх результатів на рівні вищому за базовий для вступу до вишів 3НО; $20 \%$ варіативна обов'язкова складова (6,6 год/ тиждень) - обов'язкове вивчення варіативного циклу (мистецтво, технології, музика, бізнес тощо), спрямоване на розвиток комунікативних, соціальних навичок, емоційного інтелекту - soft skills.

Приклад індивідуальної освітньої траєкторії учня (максимальне навантаження 33 год/ тиждень) за професійним профілем навчання:

- обов'язковий навчальний напрям - 50\% (16,5 год/тиждень) для вивчення предметів 3 філологічного, математичного, соціального, природничого та технічного напрямів;

- індивідуальний навчальний напрям: 30\% (9,9 год/тиждень) учні відвідують центри професійної освіти та компетенцій, спеціаліальні майстерні (воркшопи) у профільній школі, щоб визначитися із фахом; $20 \%$ варіативна обов'язкова складова (6,6 год/тиждень) обов'язкове вивчення мистецтва, технологій, музики, бізнесу тощо, розвиток комунікативних $\mathrm{i}$ соціальних навичок, soft skills [5].

Висновки. Підсумовуючи усе вищезазначене, слід наголосити на тому, що ефективність допрофільної підготовки вимагає налагодження дієвої діагностики рівня навчальних досягнень учнів основної школи, профільно-консультаційної психодіагностики з метою визначення професійних інтересів і якостей учнів для створення однорідних за підготовленістю та інтересами мікроколективів (класів, груп). Серед основних умов реалізації зазначеної концепції є організація підготовки педагогічних і керівних кадрів, забезпечення належного науково-методичного та психологічного супроводу, модернізація матеріально-технічної бази, створення нового покоління навчальних планів, програм, підручників і посібників, у тому числі й електронних, належне фінансове забезпечення.

\section{ЛІТЕРАТУРА}

1. Загородня А. А. Диференціація змісту навчання у старшій школі як ефективна умова реалізації особистісно-орієнтованої парадигми освіти. Педагогічна освіта: теорія і практика: зб. наукових праць. Серія: Педагогіка. 2018. Вип. № 25 (2-2018). С. 59-65.

2. Кушнір В. М. Профільне навчання в історії розвитку вітчизняної школи (друга половина $X I X-X X \mathrm{~cm}$.) : монографія. Умань, 2016. 409 c.

3. Лакоза Н. Організація профільного навчання в Україні та за кордоном. Педагогічний прочес: теорія і практика: зб. наукових праџь. Серія: Педагогіка. 2017. № 2(57). С. 42-48.

4. НМЦ Профільного навчання Науковометодичного центру профільного навчання Інституту післядипломної педагогічної освіти Київського університету імені Бориса Грінченка. URL: https://sites.google.com/site/smcprofil/ materials/for_organizers/material_1.

5. Нова українська школа: порадник для вчителя / Під заг. ред. Бібік Н. М. Київ, 2017. 206 с.

6. Про Національну доктрину розвитку освіти: Указ Президента України від 25.06.2013 344/2013 URL: http://zakon2.rada.gov.ua/laws/show/344/2013.

\section{REFERENCES}

1. Zahorodnia, A. A. (2018). Dyferentsiatsiia zmistu navchannia u starshii shkoli yak efektyvna umova realizatsii osobystisno-oriientovanoi paradyhmy osvity [Differentiation of the content of education in senior school as an effective condition of realization personalized-oriented paradigm of education]. Teacher education: Theory and Practice: Coll. of scientific papers. Series: Pedagogy. Vol. 25 (2-2018), pp.59-65. [in Ukrainian].

2. Kushnir, V. M. (2016). Profilne navchannia v istorii rozvytku vitchyznianoi shkoly (druha polovyna XIX - XX st.) : monohrafiia [Profile training in the history of the development of the national school (second half of XIX - XX centuries.): monograph]. Uman, 409 p. [in Ukrainian].

3. Lakoza, N. (2017). Orhanizatsiia profilnoho navchannia v Ukraini ta za kordonom [Organization of profile training in Ukraine and abroad]. Pedahohichnyi protses: teoriia i praktyka: zb. naukovykh prats. Seriia: Pedahohika. Vol. 2(57), pp.42-48. [in Ukrainian].

4. NMTs Profilnoho navchannia Naukovo- 
metodychnoho tsentru profilnoho navchannia Instytutu pisliadyplomnoi pedahohichnoi osvity Kyivskoho universytetu imeni Borysa Hrinchenka [NMC of Profile training training of the Scientificmethodical center of profile education of the Institute of postgraduate pedagogical education of the Borys Grinchenko Kyiv University]. Available at: https:// sites.google.com/site/smcprofil/materials/ for_organizers/material_1 [in Ukrainian].
5. Nova ukrainska shkola: poradnyk dlia vchytelia [New Ukrainian School: Teacher Advisor] (2018). (Ed). Bibik N. M. Kyiv, 206 p. [in Ukrainian].

6. Pro Natsionalnu doktrynu rozvytku osvity: Ukaz Prezydenta Ukrainy vid 25.06.2013 344/2013 [About the National Doctrine of Education Development: Decree of the President of Ukraine from 25.06.2013, No 344/2013]. Available at: http://zakon2.rada.gov.ua/ laws/show/344/2013 [in Ukrainian].

Стаття надійшла до редакції 09.08.2019

УДК 378.1:379.85

DOI:

Любов Гончар, кандидат економічних наук, доцент кафедри обліку і аудиту ДВНЗ “Донбаський державний педагогічний університет”

\section{ІННОВАЦІЇ У ФОРМУВАННІ ПРОФЕСІЙНОЇ КУЛЬТУРИ МАЙБУТНІХ МЕНЕДЖЕРІВ}

У статті проаналізовано проблему формування професійної культури майбутнього менеджера. Розкрито сутність понять “інноваційний процес", “освітня інновація”, “освітній інноваційний процес” 3 точки зору різних наукових підходів. Досліджується актуальність проблеми формування професійної культури майбутнього менеджера. Класифіковано освітні інновації, які дають можливість зрозуміти глибину їх ролі, завдання та функиії в організаиії освітньої діяльності (інноваційний процес, інноваційний продукт, інноваційна послуга).

Ключові слова: інновачії; майбутні менеджери; освітня інновачія; професійна культура.

Jim. 9.

Lyubov Honchar, Ph.D.(Economics), Associate Professor of the Accounting and Auditing Department Donbass State Pedagogical University

\section{INNOVATION IN THE FORMATION OF PROFESSIONAL CULTURE OF FUTURE MANAGERS}

The problem of formation the professional culture of the future managers is analyzed in the article. The essence of the concepts: "innovation process", "educational innovation", 'educational innovation process" from the point of view of different scientific approaches is revealed. The author defines the concept "educational innovation", which is considered as a complex, purposeful process of implementation, assimilation, use and dissemination in the educational activity of new ideas, orders, customs, methods, techniques, technologies, mechanisms, systems, structures, phenomena, etc., for the purpose ensuring its stability, improving efficiency and development in market conditions. The urgency of the problem of formation of professional culture of the future manager is investigated. Educational innovations are categorized, which give an opportunity to understand the depth of their role, tasks and functions in the organization of educational activities. Among which are innovations by level of innovation change, distinguishing eight ranks (orders) of innovations; by the degree of radicality of novelty (basic innovations, innovations that improve (modify), pseudo-innovations). The classification of educational innovations is given, such as: innovation process, innovative product, innovative service. Emphasis is placed on the importance of step-by-step introduction of innovation into the professional training of managers. The signs by which innovations are grouped (by: environment, place of application, focus) are identified. A model of an innovative process is proposed, covering six stages (introduction, diffusion (distribution) and modernization). The features of the educational process are highlighted, among which the focus is on its cyclicality, which corresponds to the concept of "life cycle" of innovations.

Keywords: an educational innovation; innovations; professional culture; future managers.

П

остановка проблеми. Трансформації у системі вищої освіти України та суспільні процеси, що відбулися в країні, нині вимагають нових підходів до здійснення професійної підготовки майбутні фахівців. Сьогодні одним із провідних чинників економічного успіху країни є професійна підготовка фахівців у закладах вищої освіти, рівень 